\title{
Problems of an Ergonomic Approach to the Design of a Uniform Medical Suit
}

\author{
Venera M. Yumagulova ${ }^{1}$, Elmira G. Akhmetshina ${ }^{1} \&$ Gulnaz R. Ahmetshina ${ }^{1}$ \\ ${ }^{1}$ Kazan Federal University, Kazan, Russia \\ Correspondence: Venera M. Yumagulova, Kazan Federal University, Kazan, Russia. Tel: 7-917-430-1893. E-mail: \\ yumagulova_v@mail.ru
}

Received: October 9, 2020

Accepted: December 1, $2020 \quad$ Online Published: January 14, 2021

doi:10.5430/ijfr.v12n2p184

URL: https://doi.org/10.5430/ijfr.v12n2p184

\begin{abstract}
The article presents the research in the design of a uniform medical suit and methods of implementing ergonomic requirements in the process of solving problems. The authors have chosen special uniforms for surgeons as an object of study and analysis. As a result of comparative analysis, it is noted that currently, the assortment does not meet consumer needs since many manufacturers do not attach much importance to the ergonomic requirements. The current domestic standards and regulatory and technical documents also do not always take into account the specialization and working conditions of a specialist. In the course of targeted research, the whole range of issues related to the pre-project analysis of the situation was resolved, the sequence of development of the design solution was indicated. The authors have given specific practical recommendations for the preparation of design documentation for a new model of a women's surgical blouse. The developed design documentation can serve as an information source when launching new models into industrial production since it is designed to meet the requirements for the ergonomics of surgeons.
\end{abstract}

Keywords: design, work ergonomics, ergonomic requirements, uniform medical suit

\section{Introduction}

An office uniform means a set of standard uniforms that are identified by members of a particular organization or company. Typically, police officers, emergency services, hospitals, banks, airlines, schools, etc. They want to use the same uniform at work (Wingate et al., 1986; Chong et al., 2020). Basically, there was a basic idea in the minds of managers to create uniforms, and that if the uniforms of members of the same organization are the same, a common-sense among them (Watkins \& Dunne, 2015). Will occur. The common uniform depicts a kind of solidarity. Today, wearing uniforms in organizations such as the police and military forces distinguishes this group from other people in a community, and the members of these organizations are easily recognizable by members of the community. Wearing these clothes not only makes them proud but also has a significant impact on other people in the community. For example, seeing a person wearing a police uniform will change people's mood and make them feel more secure. Therefore, most organizations prefer to wear common clothes for their employees, and there are reasons for this. Here are five reasons why we should use office uniforms (Zwolińska \& Bogdan, 2012):

1) Certain businesses, such as department stores, restaurants, and hospitals, have a special focus on their customers. The owners of these businesses demand that their workforce be integrated and eager to serve customers, so the impact of uniform uniforms becomes more important. When the workforce wears a well-fitting uniform, customers will approach them with more confidence and will trust them.

2) In some large organizations, office uniforms are used for this purpose, which saves the time and energy of employees. Because they do not have to choose clothes that are used in the workplace over and over again, they also spend a lot of money on newer clothes. So, it is rare for staff to buy new clothes.

3) If the employees of an organization wear the same office uniforms at work, there will be a special sense of commonality and belonging between them, which others can hardly achieve.

4) Creating a sense of equality among the people of an organization who use a common uniform will be created. No matter how rich or poor a person is, everyone wears the same uniform. As a result, wearing the same uniform strengthens this feeling among people. 
5) People who wear the same clothes, in addition to themselves, pay more attention to the progress of their colleagues. Shared uniforms are very important in strengthening this spirit among individuals. These characteristics that a person considers himself as a member of an organization are generally necessary for the growth and development of the collection.

At the enterprises of some industries, a person may be exposed to hazardous and harmful production factors. Clothing designed to protect human skin from these production factors is called overalls. Such clothing is issued to workers free of charge in accordance with the established standards (Suprun et al., 2003; Galeeva et al., 2018).

The main requirements that overalls must meet include protection from the effects of hazardous and harmful production factors, ensuring safe working conditions, maintaining the normal functional state of a person, his working capacity. At the same time, the clothing itself should not have a toxic effect on the human body during its operation (Abreu et al., 2018; Galeeva et al., 2018).

To develop a new model of overalls, surgery was chosen, which studies acute and chronic diseases that are treated using a surgical method.

For a successful operation, the surgeon must concentrate as much as possible on the process itself; nothing should distract him. At the same time, the static position of the surgeon's body for a long time has serious physical stress. Figure 1 shows a photo of the surgeon during the operation (Park \& Lee, 2011).

The figure shows that the muscles of the neck and shoulders, as well as the upper spine, are most susceptible to tension in surgeons. Prolonged tension leads to pain in the shoulders, which can spread to the arms, and tension provokes headaches, tinnitus, and general fatigue (Xie, 2012; Galeeva et al., 2018).

Often, prolonged tilting of the head causes overstrains of the neck muscles. This leads to an incorrect position of the first cervical vertebra, which negatively affects the structures of the jugular foramen and creates tension in the maxillofacial system. Overexertion of the wrist and elbow area causes asymmetric stress on the muscles of the shoulders and forearms. This can provoke the development of pain in the tendons (Curteza et al., 2014).

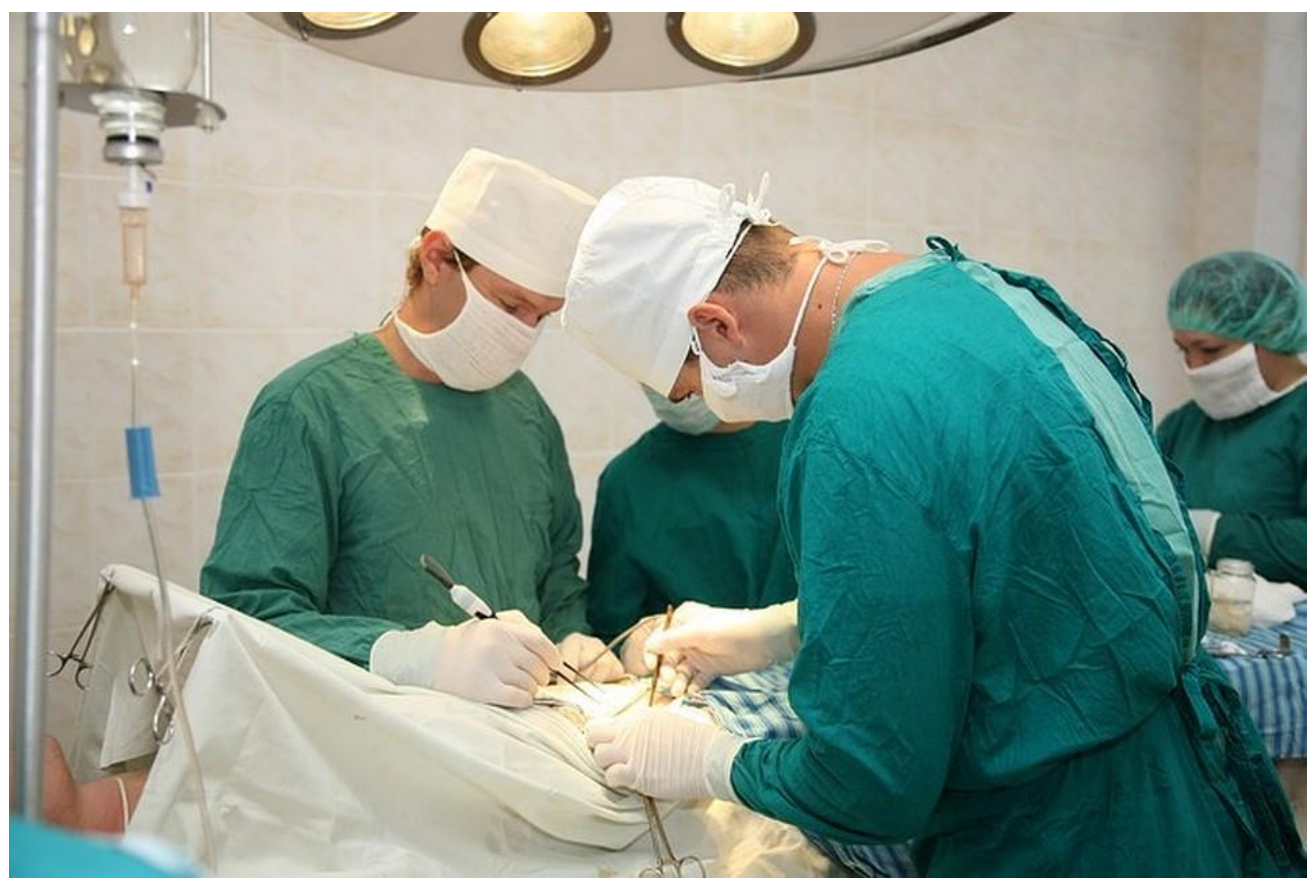

Figure 1. Surgeon during surgery

In the current study, it was tried to present the research in the design of a uniform medical suit and methods of implementing ergonomic requirements in the process of solving problems. In this regard, surgery puts forward the following requirements for overalls:

- ergonomic requirements; 
- the suit consists of a robe, trousers, a blouse, hats, and gloves;

- external characteristics - cut, silhouette, colors;

- materials for manufacturing.

\section{Method}

As mentioned earlier, this paper, it was aimed to present the research in the design of a uniform medical suit and methods of implementing ergonomic requirements in the process of solving problems. The authors have chosen special uniforms for surgeons as an object of study and analysis. For this purpose, two different types of methods were used:

1. Theoretical methods: studying scientific literature, regulatory and technical documents (analysis, systematization, classification, generalization, and comparison).

2. Empirical methods: observation, experiment, document analysis, peer review method.

\section{Results}

Ergonomic requirements for clothing are understood as a set of requirements for properties that characterize the compliance of clothing with anatomical, physiological and psychological requirements of a person, ensuring the convenience and safety of using products, optimizing all physical and mental stress associated with obtaining a beneficial effect.

The development of a rational design of workwear should be based on ergonomic schemes of the basic movements of the worker, physical and mechanical indicators of the properties of the selected materials, and a set of requirements for this type of clothing (Manlow, 2009). Figure 2 shows an ergonomic diagram of the surgeon's main movements and body position.

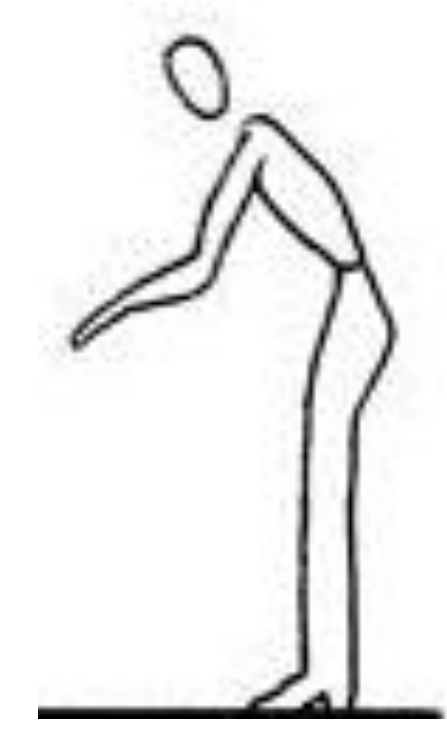

Figure 2. Ergonomic diagram of the surgeon's main movements and body position

In accordance with GOST EN 13795 - 2011, "Surgical clothing and underwear used as medical products for patients, surgical personnel and equipment" (Tran et al., 2015), the clothing for the surgeon must contain antibacterial impregnation to protect against dangerous contamination. Due to this, biological fluids falling on clothes are not absorbed but simply slide down. Suits and robes are made of fabrics with a high content of natural raw materials to significantly improve the hygiene and hygroscopicity of the product. If artificial fiber is used in small quantities, this fact prolongs the life of the garment and increases its wear resistance. The combination of cotton, viscose, and polyester is defined by GOST 11518 - 88 "Shirt fabrics from chemical threads and mixed yarns" (Rissanen et al., 2008).

Thus, the fabric for the manufacture of a surgical suite must meet the following requirements: washing strength, air 
permeability, hygroscopicity, shrink resistance, and thermal properties.

To develop a new model of a surgical women's blouse, an analysis of analog models of the following companies for the production of medical clothing in the Republic of Bashkortostan was carried out: Tekhnoavia-Ufa LLC, Standard-Zashchita LLC, SpetsKomplekt LLC, Medis LLC. The analysis of analog models is to study all the advantages and disadvantages of models in accordance with their purpose, standards, and requirements (Kadyjrova et al., 2019). Figure 3 shows analog models of surgical suits taken from the websites of online stores of the above companies.

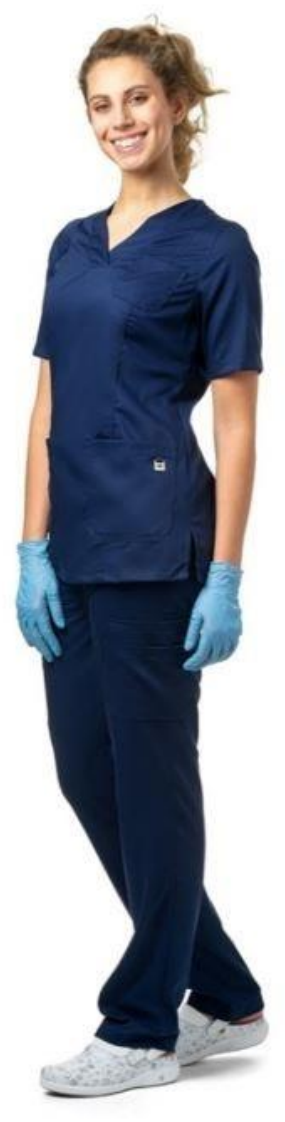

a)

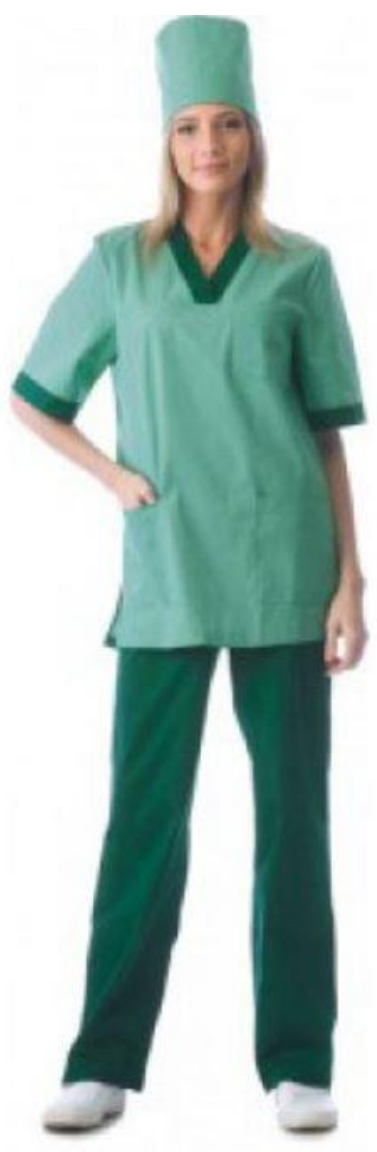

b)

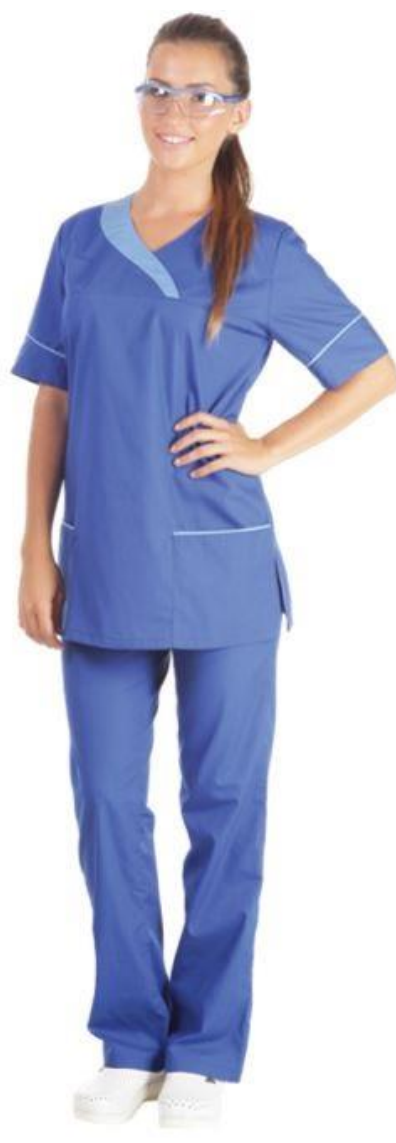

c)

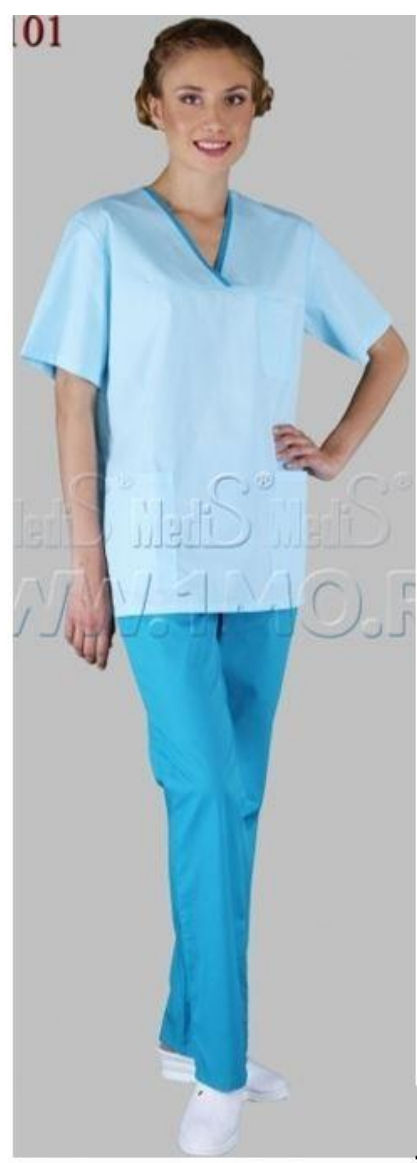

d)

Figure 3. Analog models of women's surgical suits: a) "Technoavia-Ufa"; b) "Standard-protection"; C) "Special Kit"; d) " MEDIS»

Due to the difficult epidemiological situation in the country, the study was carried out using the catalogs of online stores of the above-listed manufacturers of special clothing. The objective of the study was to identify model features in the design of women's surgical blouses, as well as their color scheme. The results of the research are necessary for the development of models-proposals of women's surgical blouses. The results of the study are presented in Table 1. The table also shows GOSTs the manufacturers comply with to produce overalls for surgeons (Besshaposhnikova et al., 2013). 
Table 1. Results of research of models of women's blouses

\begin{tabular}{|c|c|c|c|c|}
\hline $\begin{array}{l}\text { Model features in } \\
\text { the design }\end{array}$ & Tekhnoavia-Ufa LLC & $\begin{array}{l}\text { Standard-Zashchita } \\
\text { LLC }\end{array}$ & SpetsKomplekt LLC & Medis LLC \\
\hline $\begin{array}{l}\text { Number of models } \\
\text { offered }\end{array}$ & 11 & 3 & 3 & 11 \\
\hline Silhouette & $\begin{array}{l}\text { semi-close-fitting - } 5 \\
\text { straight - } 6\end{array}$ & $\begin{array}{l}\text { semi-close-fitting - } 1 \\
\text { straight - } 2\end{array}$ & straight - 3 & $\begin{array}{l}\text { semi-close-fitting } \\
-8 \\
\text { straight - } 3\end{array}$ \\
\hline Cut & sewn-in - 11 & sewn-in - 3 & sewn-in - 3 & sewn-in - 11 \\
\hline Neck shape & $\begin{array}{l}\text { round - } 1 \\
\text { V-neck - } 10\end{array}$ & V-neck - 3 & V-neck - 3 & V-neck - 11 \\
\hline Sleeve length & short - 11 & short - 3 & short - 3 & short - 11 \\
\hline Length & hip-line - 11 & below the hip line - 3 & below the hip line - 3 & $\begin{array}{l}\text { hip-line }-8 \\
\text { below the hip line } \\
-3\end{array}$ \\
\hline $\begin{array}{l}\text { The presence of a } \\
\text { yoke/relief }\end{array}$ & $\begin{array}{l}\text { yoke: } 1 \\
\text { reliefs } 9 \text { - shoulder; } 2 \\
\text { - armhole }\end{array}$ & $\begin{array}{l}\text { yoke: } 3 \\
\text { reliefs: armhole - } 1\end{array}$ & yoke: 3 & $\begin{array}{l}\text { yoke: } 6 \\
\text { reliefs: } \quad 4 \\
\text { shoulder; } \quad 2 \\
\text { armhole; } 3 \text { - yoke }\end{array}$ \\
\hline Pockets & $\begin{array}{l}\text { jetted - } 1 \\
\text { patch - } 5 \\
\text { with cord seams - } 5\end{array}$ & patch - 3 & patch - 3 & $\begin{array}{l}\text { patch }-4 ; \\
\text { with cord seams - } \\
7\end{array}$ \\
\hline Finishing & $\begin{array}{l}\text { contrast-colored } \\
\text { piping - } 7\end{array}$ & $\begin{array}{l}\text { contrast-colored piping } \\
-1\end{array}$ & $\begin{array}{l}\text { contrast-colored } \\
\text { piping - } 3\end{array}$ & $\begin{array}{l}\text { contrast-colored } \\
\text { piping - } 5\end{array}$ \\
\hline Color spectrum & $\begin{array}{l}\text { white, blue, light } \\
\text { blue, pink, green, } \\
\text { gray, patterned }\end{array}$ & $\begin{array}{l}\text { blue, light blue, pink, } \\
\text { green }\end{array}$ & $\begin{array}{l}\text { blue, light blue, } \\
\text { purple }\end{array}$ & $\begin{array}{l}\text { beige, purple, } \\
\text { pink, blue, light } \\
\text { blue, orange, gray, } \\
\text { patterned }\end{array}$ \\
\hline GOSTs & $\begin{array}{l}\text { GOST 12.4.280-2014 } \\
{[12]}\end{array}$ & - & GOST 9896-88 [13] & - \\
\hline
\end{tabular}

According to the results of the study, we can say that:

- The offered models of women's blouses from Tekhnoavia-Ufa LLC, Standard-Zashchita LLC, SpetsKomplekt LLC have a general-purpose of medical clothing without specialization. Medis LLC indicates in the description of the models the purpose of medical clothing, considering its specialization;

- Manufacturers of overalls for surgeons from Tekhnoavia-Ufa LLC in the description of each model of a women's blouse indicate "Not a medical product;

- Tekhnoavia-Ufa LLC and SpetsKomplekt LLC indicate GOST 12.4.280-2014 and GOST 9896-88 in the description of the proposed models of women's blouses, respectively. These documents prescribe the general requirements for the design and materials of medical clothing. Consequently, the given GOSTs do not consider the specialization of the work of surgeons.

\section{Discussion}

Based on the analysis of analog models, research results, and requirements for a women's surgical blouse, 3 model proposals with different design solutions and colors have been developed. Figure 4 shows the proposed models of a surgical blouse for women.

In accordance with the ergonomic scheme of the main movements of the surgeon and the position of the body (see Figure 2), all models-proposals have a V-shaped neck for the convenience of quick dressing over the head. The 
choice of this shape of the neck is also explained by the fact that during the operation, the surgeon's head is tilted forward, and this shape of the neck does not have a "suffocating" effect. During the operation, the surgeon's arms are bent, so the sleeves are above the level of the elbow. The choice of colors is explained by the fact that these colors do not reflect the light falling from the operating lamps, which reduces the surgeon's eye strain.

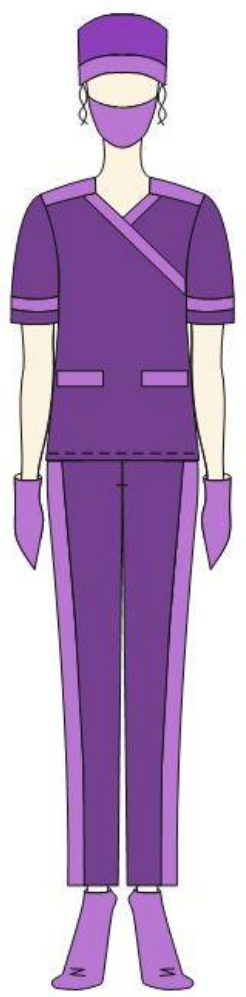

Model №1

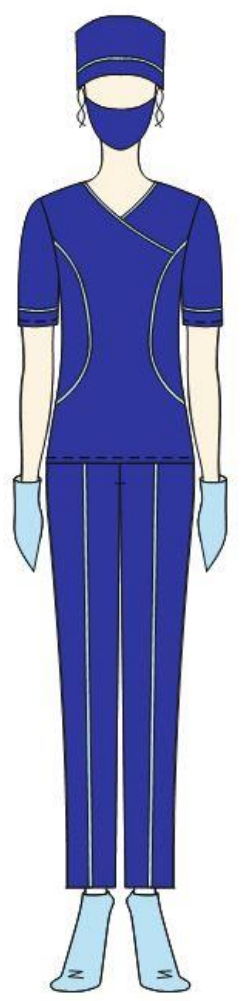

Model №2

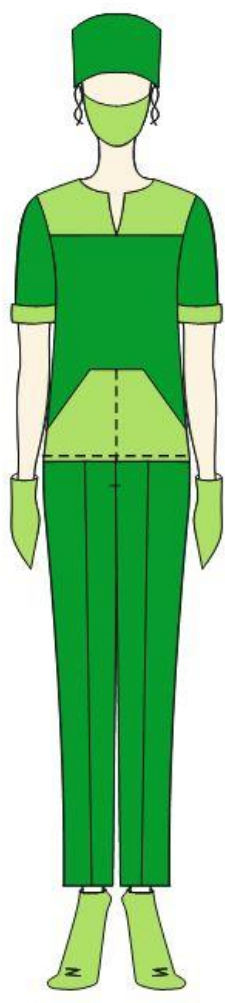

Model№3

Figure 4. Models-offers of surgical women's blouse

For the development of a new model of a blouse for women, model No. 2 was chosen, as it has decorative and constructive lines in the form of reliefs, coming from the armhole line, giving a feminine look, despite the fact that it is protective clothing. Also, this model has pockets located in embossed seams. In contrast, the blouse model No. 1 has welt pockets with a leaf, which increases the complexity of its processing. Model No. 3 differs in the shape of the neck, which also increases the complexity of its processing. Figure 5 shows a technical sketch of a blouse model. 

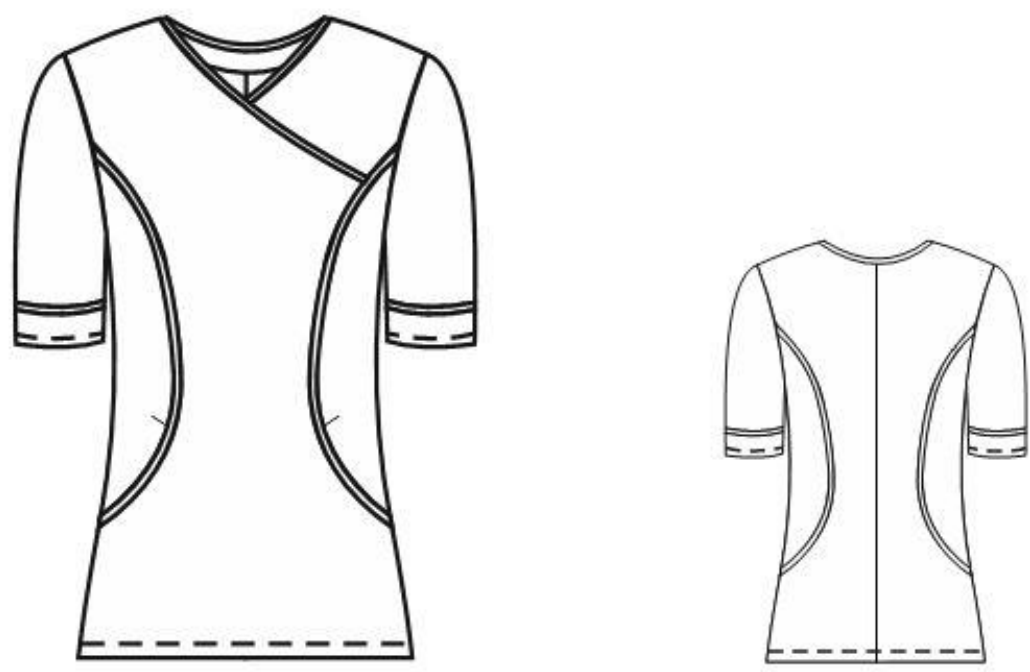

Figure 5. Technical sketch of the blouse model

Blouse of a semi-adjacent silhouette with cut-off side bodies extending from the armhole line to the side seam. In front of the V-neck, the neckline goes to the relief line of the cut-off barrel. Seam pockets on cut-off barrels. Back with the middle seam. The sleeve is one-seam, short with a stitched cuff at the bottom of the sleeve. There is piping along the edge of the neckline, cut-off barrels, and in the cuff seam.

Recommended materials are blended and barrier fabrics (tisi, satori), anti-static micro polyester, polyester, and polyester-carbon fabrics.

Recommended sizes: bust 80-96 cm, height $158-176 \mathrm{~cm}$.

To build a drawing of the basic design of a blouse for a typical shape, the EMKO TsOTShL technique was chosen. It contains all the necessary data for the calculation and construction of drawings of designs of women's shoulder and waist clothing for typical and atypical female figures (Kadyjrova et al., 2020). A distinctive feature of this technique is the presence of a preliminary calculation of the structure, the essence of which is to determine the width of the armhole and compare it with the minimum tabular values of the EMCO TsOTShL. The values of dimensional attributes for building a drawing for a typical shape of 170-92-100 are taken from GOST 17522-72.

The TsNIISHP research showed that with the improvement of the basic characteristic movements in the process of work, the measurements of a number of areas of the figure change significantly. These measurements include front waist length, back length to waist, back and chest width, leg length, distance from the waistline to the level of the gluteal fold (arc-wise) (Manlow, 2009).

According to the presented ergonomic diagram of the main movements of the surgeon and the position of the body (see Figure 2), we can say which measurements of the body parts change during work: the width of the back and chest in a narrow place. The width of the back is increased due to the inclination of the body forward and the lowered shoulders. Therefore, the width of the back in a narrow place increases, and the width of the shelf in a narrow place decrease. Therefore, to build a drawing of the basic design of a blouse, the choice of the number of allowances for free fit was carried out, taking into account the range of overalls and the ergonomic requirements for it.

To prove the observance of ergonomic requirements when choosing the amount of free-fitting increments in those parts of the structure that change during operation, Table 2 presents a comparison of the increments for semi-fitted blouses for everyday and special purposes. 
Table 2. Comparison of the values of the widening for free fit

\begin{tabular}{|c|c|c|c|c|}
\hline \multirow{2}{*}{ Widening name } & \multirow{2}{*}{ Designation } & \multicolumn{2}{|c|}{ Value, $\mathrm{cm}$} & \multirow{2}{*}{$\begin{array}{l}\text { Deviations from } \\
\text { the } \\
\text { widening }\end{array}$} \\
\hline & & daily & special & \\
\hline Arm-hole widening & Ahw & 1.5 & 2.5 & +1.0 \\
\hline Back width widening & Bww & 1.0 & 1.4 & +0.4 \\
\hline Chest width widening & Cww & 0.8 & 0.5 & -0.3 \\
\hline Back neck width widening & Bnww & 0.5 & 0.7 & +0.2 \\
\hline
\end{tabular}

Based on the selected dimensional characteristics and widening for free fit, the basic and model designs were built in accordance with the technical sketch of the blouse. The construction is carried out in Gratsiia computer-aided design system, the "Design and Modeling" subsystem. This system uses special methods for the automatic execution of geometric and technological operations, which ensures high speed and accuracy of the decisions made.

The design process is possible by any of the methods for designing clothes for typical and individual figures. There is an important function that combines the parameters of interconnected parts. That is, when one of the parts is changed, the rest is automatically rebuilt. This program, in addition to the ability to develop basic and auxiliary patterns of all sizes, provides for the creation of timesheets, specifications of patterns, and normalization maps. Figure 6 shows a schematic drawing of the basic and model designs of a blouse.

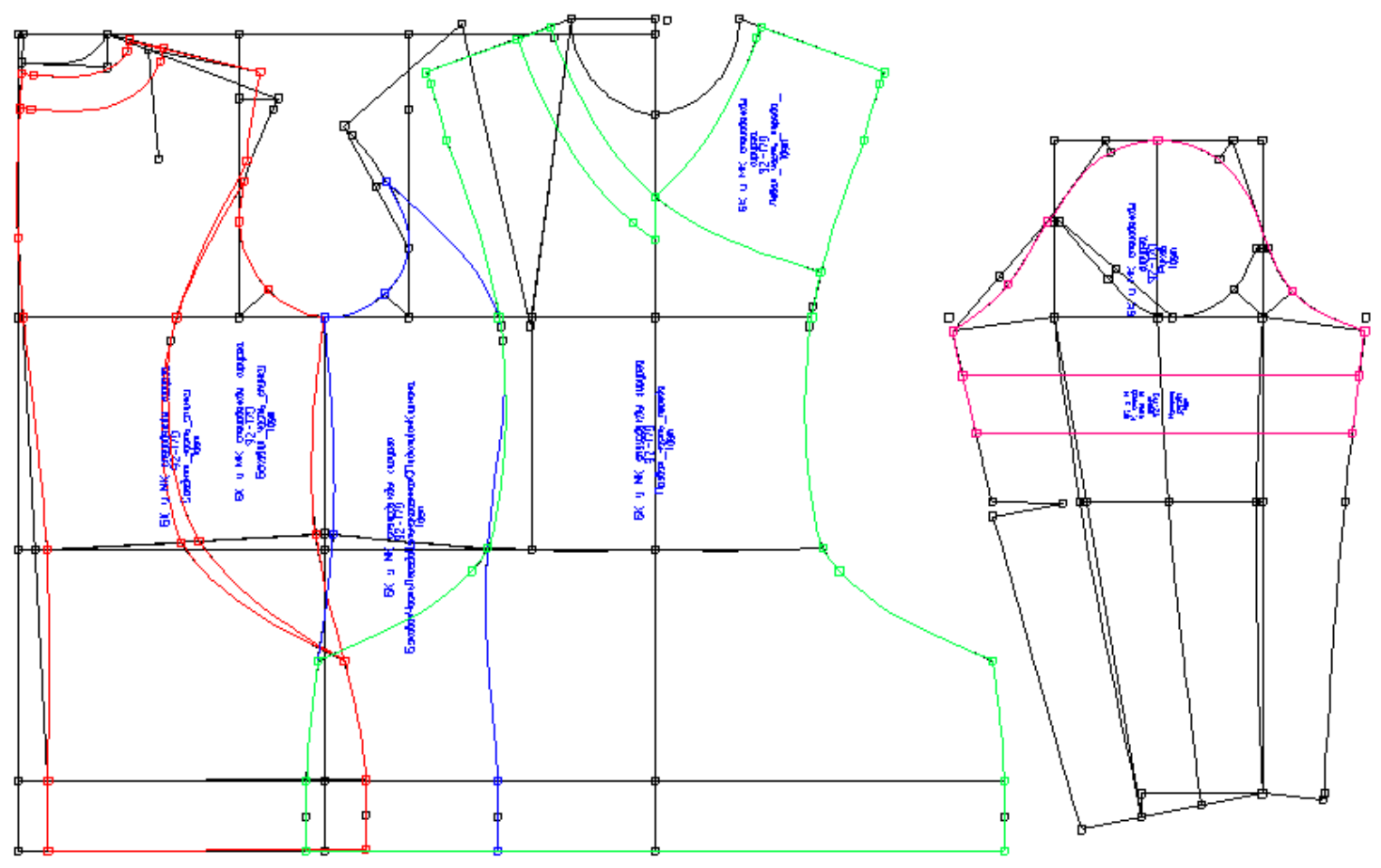

Figure 6. Drawing diagram of the basic and model blouse design

A blouse model was made to check balance and fit. The layout was checked on a suitably sized mannequin. In accordance with the criteria for correct fit and balance of garments, an analysis of the structural and model lines of the blouse layout was carried out to clarify the position and configuration of these lines, as well as the volume of the product and the sleeve. After analyzing the layout, all changes were transferred to the patterns and drawings of the blouse designs.

When designing patterns, technological widening for seams and hem are made in the contours of each part. For the 
designed blouse, the following values of technological allowances were selected: for connecting cuts and hem of the sleeve bottom $-1.0 \mathrm{~cm}$; for the hem of the bottom of the product $-3.0 \mathrm{~cm}$. Figure 7 shows a diagram of the templates of the main and derived patterns-standards for a blouse.

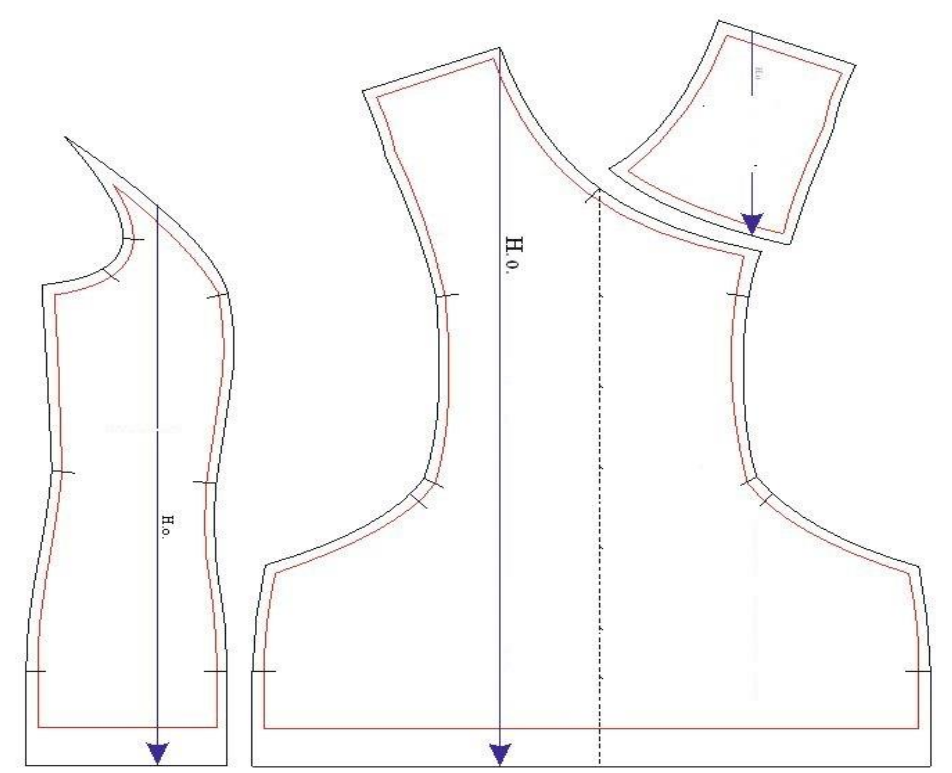

a) details of the transfer

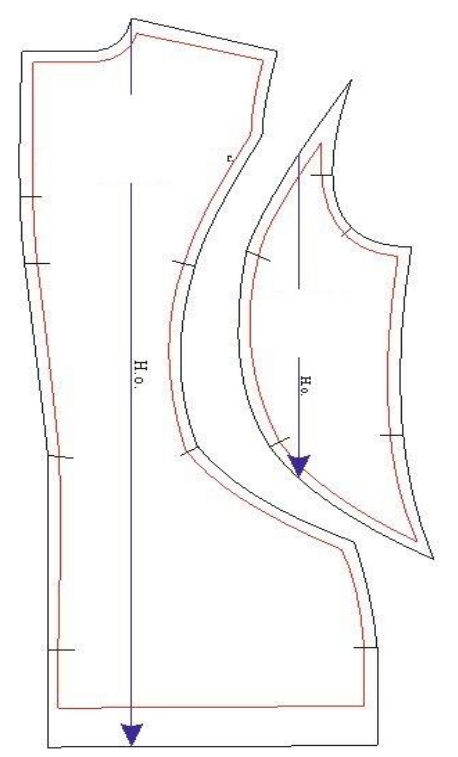

b) back details

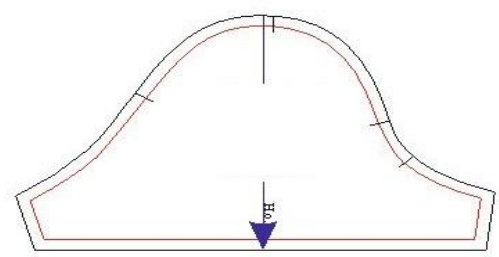

c) detail of the sleeve

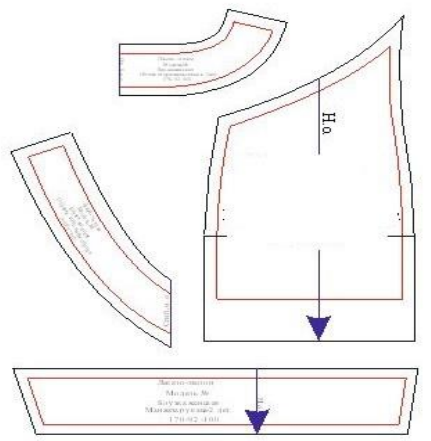

d) details: pocket lining, front and back neck facings, sleeve cuff

Figure 7. Diagram of templates for basic and derived patterns-standards for a blouse

When choosing processing methods, the progressiveness of technologies was considered, which would ensure a high level of labor mechanization, minimal labor costs, high and stable quality of garments, as well as the versatility of technological sequences of processing products will make it possible to use them on one equipment. Figure 8 shows the methods for processing blouse knots. 


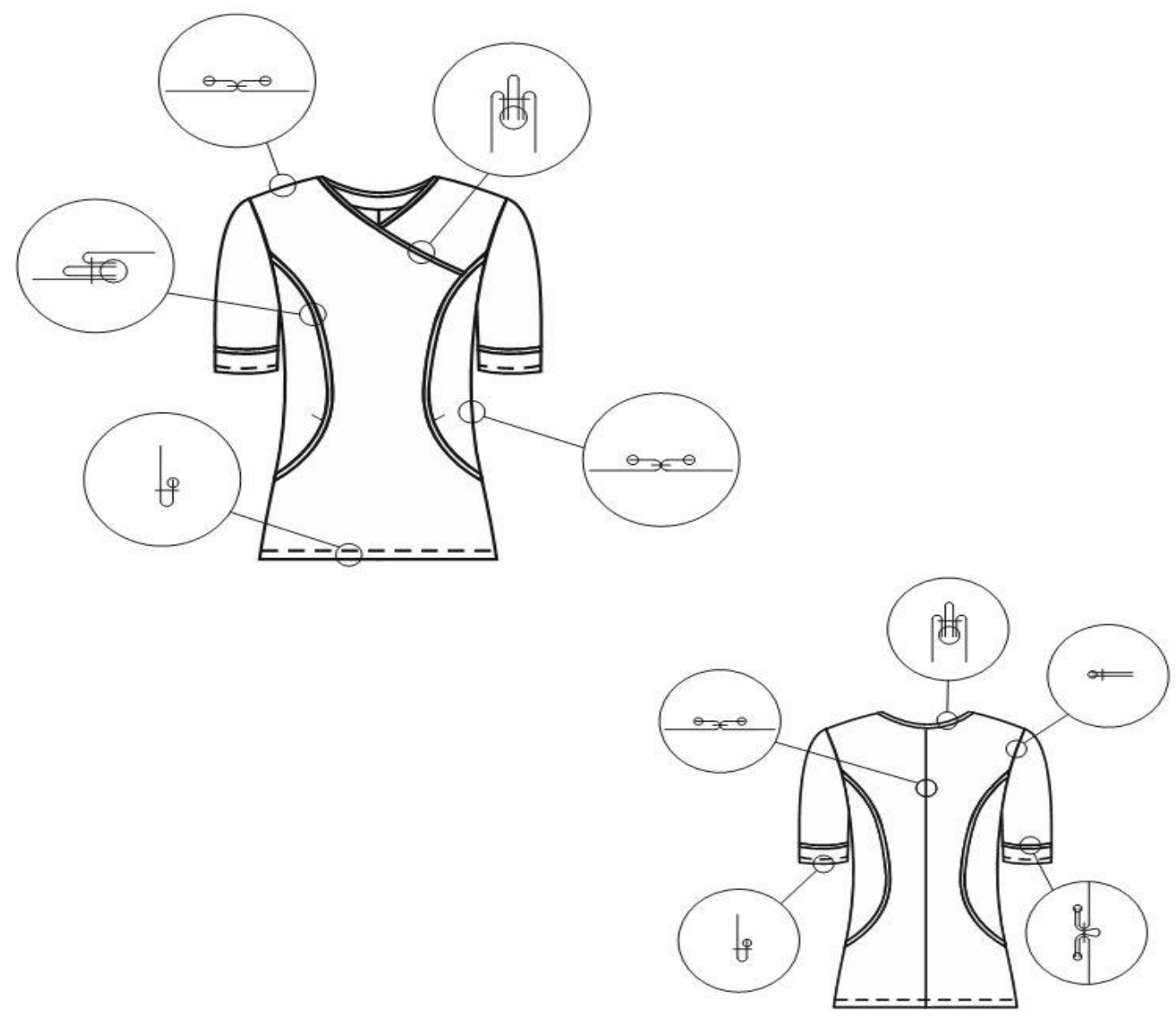

Figure 8. Methods of processing blouse nodes

Based on the results of the design and research work, design documentation for a new model of a women's surgical blouse was developed, including drawings of the basic and model design, a model of a blouse, basic and derivative reference patterns, methods of processing blouse knots. The new model of the women's surgical blouse was developed considering the ergonomics of the work of surgeons. The developed design documentation can serve as an information source when launching new models into industrial production since it is designed to meet the requirements for the ergonomics of surgeons.

\section{Acknowledgments}

The work is performed according to the Russian Government Program of Competitive Growth of Kazan Federal University.

\section{References}

Abreu, M. J., Silva, M. E., Schacher, L., \& Adolphe, D. (2003). Designing surgical clothing and drapes according to the new technical standards. International Journal of Clothing Science and Technology, 15(1), 69-74. https://doi.org/10.1108/09556220310461178

Besshaposhnikova, V. I., Zagoruiko, M. V., \& Pulina, K. I. (2013). Method for fire protection of wool-containing cloths for special clothing. Fibre Chemistry, 44(6), 368-371. https://doi.org/10.1007/s10692-013-9462-8

Chong, S. C., Tan, F. Y., Mah, P. Y., \& Low, C. W. (2020). Consumers' Purchase Intention Toward Ergonomic Footwear in Malaysia. International Journal of Financial Research, 11(2), 10-19. https://doi.org/10.5430/ijfr.v11n2p88

Curteza, A., Cretu, V., Macovei, L., \& Poboroniuc, M. (2014). Designing functional clothes for persons with locomotor disabilities. Autex Research Journal, 14(4), 281-289. https://doi.org/10.2478/aut-2014-0028

Galeeva, Z. N., Yao, M. K., Emanova, J. G., \& Pushkar, T. (2018). Project thinking as the basis of professional 
competence of the designer. Amazonia Investiga, 7(15), 133-138. Retrieved from https://amazoniainvestiga.info/index.php/amazonia/article/view/429

Kadyjrova, L. H., Akhmetshina, E. G., Zaripova, L. R., \& Peremislov, I. A. (2019). Professional development of bachelor designers by means of information and communication technologies. International Journal of Innovative Technology and Exploring Engineering, 9(1), 5119-5122. https://doi.org/10.1016/j.compedu.2014.07.006

Kadyjrova, L. H., Mukhametzyanova, L. R., \& Kadyirov, T. R. (2020). Essence of Art-Project Activity and Development of Artistic-Design Competence/Esencia de la actividad del proyecto de arte y desarrollo de la competencia del diseno artistico. Utopía y Praxis Latinoamericana, 25(S7), 369-376. https://doi.org/10.5281/zenodo.4009753

Manlow, V. (2009). Designing clothes: Culture and organization of the fashion industry. Transaction Publishers.

Park, J. H., \& Lee, J. R. (2011). Analysis on patent trends for medical clothing of Korea and USA. Journal of the Korean Society of Clothing and Textiles, 35(4), 488-500.

Rissanen, S., Jousela, I., Jeong, J. R., \& Rintamäki, H. (2008). Heat stress and bulkiness of chemical protective clothing impair performance of medical personnel in basic lifesaving tasks. Ergonomics, 51(7), 1011-1022. https://doi.org/10.1080/00140130701813160

Suprun, N., Vlasenko, V., \& Ostrovetchkhaya, Y. (2003). Some aspects of medical clothing manufacturing. International Journal of Clothing Science and Technology, 15(3), 224-230. https://doi.org/10.1108/09556220310478323

Tran, T. A. D., Arnold, M., Schacher, L., Adolphe, D. C., \& Reys, G. (2015). Development of personal protection equipment for medical staff: case of dental surgeon. AUTEX Research Journal, 15(4), 280-287. https://doi.org/10.1515/aut-2015-0002

Watkins, S. M., \& Dunne, L. (2015). Functional clothing design: From sportswear to spacesuits. Bloomsbury Publishing USA.

Wingate, S. B., Kaiser, S. B., \& Freeman, C. M. (1986). Salience of disability cues in functional clothing: A multidimensional approach. Clothing and Textiles Research Journal, 4(2), 37-47. https://doi.org/10.1177/0887302X8600400206

Xie, K. (2012). Empirical study of the National Health Service in UK and the US Medical Care System. International Journal of Financial Research, 3(1), 33-39. https://doi.org/10.5430/ijfr.v3n1p33

Zwolińska, M., \& Bogdan, A. (2012). Impact of the medical clothing on the thermal stress of surgeons. Applied Ergonomics, 43(6), 1096-1104. https://doi.org/10.1016/j.apergo.2012.03.011

\section{Copyrights}

Copyright for this article is retained by the author(s), with first publication rights granted to the journal.

This is an open-access article distributed under the terms and conditions of the Creative Commons Attribution license (http://creativecommons.org/licenses/by/4.0/). 